\title{
A mediação estética como base investigativa para a definição de um estatuto epistemológico para o Campo do Design
}

ARTIGO

\author{
The aesthetic mediation as an investigative basis for the \\ definition of an epistemological statute for the Design Field
}

Fabiana Oliveira Heinrich

http://lattes.cnpq.br/4318694756169261

\section{Resumo}

Este artigo propõe uma investigação no Campo do Design a partir de um estudo da disciplina da Estética e sua capacidade de mediação na construção de artefatos culturais, com vistas à definição de um estatuto epistemológico para o Campo em questão. Ao tomar os escritos de Eagleton (A ideologia da Estética, 1993), Wolff (A produção social da Arte, 1982) e Harvey (Condição pós-moderna, 2010), problematizamos a noção hegemônica de que elementos estéticos podem ser compreendidos por si mesmos, e apontamos para a presença de um caráter ideológico que orienta a sua construção, uso e reprodução. Com efeito, buscamos compreender, no Campo do Design, como a Estética reproduz e materializa valores econômicos, políticos e sociais, e como tal reprodução deve ser considerada no estudo e na configuração de produtos do supracitado Campo.

\section{Palavras-chave}

Campo do Design, Estética, Mediação

Estética, Epistemologia, Ideologia.

\section{Abstract}

This article proposes an investigation in the Design Field, based on the study of the discipline of Aesthetics and its mediation capacity in the construction of cultural artifacts, in order to define an epistemological statute for the Field in question. In taking the writings of Eagleton (A ideologia da Estética, 1993), Wolff (A produção social da Arte, 1982) and Harvey (Condição pós-moderna, 2010), we problematize the hegemonic notion in which aesthetic elements can be understood by themselves, and point to the presence of an ideological character that guides their construction, usage and reproduction. Indeed, we seek to understand, in the Design Field, how Aesthetics, through its use, reproduce and materializes economic, political and social values, and how such reproduction should be considered in the study and configuration of produtcs in the aforementioned Field.

\section{Keywords}

Design Field, Aesthetics, Aesthetic

Mediation, Epistemology, Ideology. 
Contrariamente à rasa e hegemônica concepção contemporânea, empregada especialmente pelo Campo do Design, de que Estética corresponde apenas ao estudo e compreensão de aspectos visuais de materializações no mundo ${ }^{[1]}$ - percepção essa compreendida depreciativamente como inconsistente e inútil -; pelo viés filosófico e sociológico, a Estética detém também o domínio do estudo de questões da percepção e do sensível. Deste modo, neste artigo pretendemos, através da apresentação e do debate de conceitos de Estética oriundos dos Campos da Arte, da Filosofia e da Sociologia, discutir como esta disciplina pode ser compreendida no Campo do Design enquanto mediação, isto é, enquanto instância empregada para a materialização de valores e concepções de cunho econômico, político e social. A partir de um olhar crítico e reflexivo dos princípios e hipóteses formadores e presentes nesses conceitos, buscamos contribuir para a ampliação da Estética como elemento-chave no estabelecimento de um contorno mais nítido do Campo do Design, com vistas à definição de um estatuto epistemológico para este.

Assim, partimos do estudo da compreensão estética proposta por Terry Eagleton em A Ideologia da Estética ${ }^{[2]}$ (1993), para então fundamentarmos a questão da mediação estética com Janet Wolff em $A$ produção social da $\operatorname{Arte}^{[3]}$ (1982) e, por fim, fecharmos o estudo com questões contemporâneas acerca do papel social e político da Estética através de David Harvey em Condição pós-moderna ${ }^{[4]}$ (2010). Atemo-nos a autores dos Campos da Arte, Filosofia e Sociologia, pela necessidade de buscar na gênese da disciplina da Estética fundamentos para a sua aplicação e seu entendimento na prática contemporânea do Campo do Design.

Ademais, é justamente por ainda imperar no Campo do Design a equivocada noção de que "gosto não se discute", a noção passadista de que o gosto é algo inerente e singular ao indivíduo ou ao agente social, mes-

\footnotetext{
[1] Aqui referimo-nos a discussões em salas de aula experienciadas ou relatadas por colegas de distintas instituições espalhadas pelo Brasil, bem como o uso do termo "estética" em textos que apenas apresentam, descrevem e analisam produtos de Design a partir - e unicamente - de seus formantes visuais.

[2] EAGLETON, Terry. A ideologia da Estética. Rio de Janeiro: Jorge Zahar Editores, 1993.

[3] WOLFF, Janett. A produção social da arte. Rio de Janeiro: Zahar Editores,1982.

[4] HARVEY, David. Condição pós-moderna. São Paulo: Loyola, 2010.
}

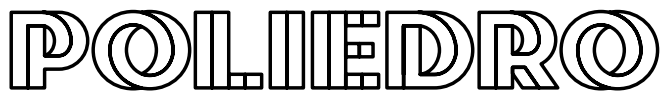


mo depois de inúmeros estudos dos anos 1970 e $1980^{[5]}$ já terem ampla divulgação e assimilação; que advogamos a desmistificação do mito da criação para explicitar como o gosto, as formas e valores estéticos são construídos socialmente. É-nos curiosíssimo verificar como essas noções são recorrentemente vinculadas como suporte dos desacertados valores do sistema econômico em vigor, os quais acabam por determinar a dinâmica das relações sociais contemporâneas também no Campo do Design.

Com efeito, começamos por uma apresentação e debate das ideias de Eagleton (1993), que descreve que a Estética nasceu como disciplina em um momento propenso: a conjuntura política iluminista, em que as questões da alma deveriam ser passíveis de ser explicadas, do contrário governos nunca conseguiriam exercer seus poderes de modo completo, pois os cidadãos jamais se sentiriam pertencentes a determinados valores humanos, se esses valores não tomassem conta de seus anseios mais íntimos. Era preciso uma possibilidade de entendimento disso que se considerava existir no interior mais profundo dos seres humanos que hoje chamamos de subjetividade - por outra modalidade teórica. Conforme Eagleton questiona (1993, p. 17), como os governos poderiam deixar a experiência humana fora das concepções dirigentes de uma sociedade? Logo, estando esta noção próxima das noções de afetos e modos, e estas, próximas da apreensão e internalização de uma ideologia, tal construção repercute largamente formando aquilo que Bourdieu $^{[6]}$ (2012) denomina habitus, isto é, um conjunto de valores e crenças entendidos como naturais, mas que na verdade correspondem a construções sociais que foram naturalizadas, e sobre as quais ninguém se questiona - como no recorrente pensamento: "é assim, porque o é".

Deste modo, é a partir deste panorama que cabe-nos compreender como os códigos, elementos estéticos ditados pelas classes dominantes, disfarçaram-se nos produtos ${ }^{[7]}$ culturais - aqui para nós, no Campo

[5] Aqui pensamos nos escritos de Pierre Bourdieu, especialmente: BOURDIEU, Pierre. A Distinção: Crítica Social do Julgamento. São Paulo: Edusp/ Porto Alegre: Zouk, 2007. BOURDIEU, Pierre. A produção da crença: contribuição para uma economia dos bens simbólicos. Porto Alegre: Zouk, 2008.

[6] BOURDIEU, Pierre. O Poder Simbólico. 16ª edição. Rio de Janeiro: Bertrand Brasil, 2012.

[7] Neste artigo usaremos os termos "artefato", "objeto" e "produto" como equivalentes,

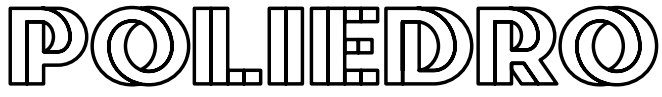


do Design. Neste ponto, entram os escritos de Janet Wolff (1982), que abordam como a Arte é uma produção social e não uma atividade excepcional ou carismática que somente poucos - os dotados de um talento inato e inexplicável - podem exercer. Ao considerarmos o Campo da Arte como homólogo ao Campo do Design, a partir dos escritos da supracitada autora, buscaremos esclarecer como os códigos sociais são reproduzidos nos produtos da indústria cultural, principalmente pelo viés estético - por isso, falamos de uma mediação estética. Logo, em que medida características e configurações formais podem reproduzir valores econômicos, políticos e sociais?

Por fim, trazemos os escritos de David Harvey (2010) para compreender e colimar a proximidade destes valores na produção cultural atual e a sua relação com o sistema econômico vigente - e aqui, atemo-nos novamente a observações próximas à prática social do Campo do Design. Harvey (2010) discorre acerca de uma mudança na estrutura de sentido da modernidade para a dita pós-modernidade: uma sensação de fragmentação e efemeridade antes inexistente, ou não latente, que surgiu a partir da dominação cultural por parte das práticas econômicas do capitalismo avançado. Essa mudança de sentido, de valor da experiência, corresponde a uma mudança na maneira como nos relacionarmos com produtos da indústria cultural, fenômeno que recai em uma potencial compreensão da Estética no âmbito do Campo do Design. Assim, em uma época de "imperialismo do gosto" (HARVEY, 2010, p. 17-18), faz-se necessário desmistificar como esse imperialismo é construído e eficazmente difundido, naturalizado, recriando a própria hierarquia de valores e significações do modelo econômico vigente; pois sendo o processo estético um processo de criação e observação, temos que atentar para os meios como estes operam - e é o que tentaremos fazer a seguir.

\section{Considerações primeiras sobre a Estética}

Eagleton (1993, p. 7) afirma ser relevante o estudo da Estética, uma vez que encontramos na investigação dessa disciplina um acesso à compreensão de certas questões centrais do pensamento humano, como

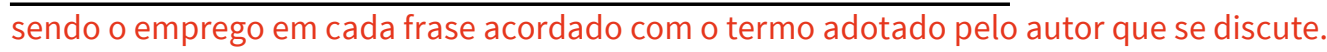

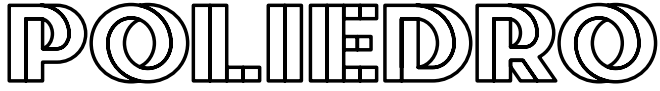


questões sociais, políticas e éticas, as quais se encontram no centro da luta de classes pela hegemonia política. Especialmente no contexto do modernismo e do dito pós-modernismo, em que a cultura parecer ser uma categoria-chave para a análise da compreensão da sociedade capitalista avançada - período histórico em que a prática cultural encontra-se destituída de sua relevância social tradicional, rebaixada a um ramo da produção generalizada de mercadorias - faz-se necessária, portanto, a compreensão das dinâmicas inerentes a tal configuração, uma vez que, para o Campo do Design, esta reflexão apresenta-se de grande relevância face ao fato de que este encontra-se circunscrito na indústria de bens culturais e simbólicos. A Estética tem, assim, papel dominante na sociedade - e, consequentemente, na prática social do Campo do Design - a partir do pensamento moderno, configurando-se como um conceito versátil, pois sua construção é inseparável, conforme afirma o supracitado autor (EAGLETON, 1993, p. 8), da construção das formas ideológicas dominantes da sociedade de classes moderna e de todo um novo formato da subjetividade apropriado a esta ordem social. Deste modo, seria em função desta configuração, e não de um despertar de homens e mulheres para o valor superior da poesia e da pintura, por exemplo (EAGLETON, 1993, p. 8), ou, no Campo do Design, da visão equivocada da possibilidade de compreensão de um produto a partir de sua configuração puramente formal; que a Estética assume um papel tão intempestivo na herança intelectual presente.

Destarte, considera-se que conceitos estéticos começam a exercer um papel central e intensivo na constituição da ideologia dominante, e são utilizados por razões políticas. Sendo assim, segundo Eagleton (1993, p. 12-13), a Estética constitui-se como um conceito burguês, no sentido histórico e literal, criado e nutrido pelo lluminismo, pois ela, enquanto categoria teórica, está articulada ao processo material pelo qual a produção cultural, em um estágio inicial da sociedade burguesa, ganhou "autonomia" em relação às várias funções sociais a que ela servia tradicionalmente, isto é, os produtos se tornam bens de consumo no mercado, existindo para nada e para ninguém em particular, ou seja, existindo prioritariamente a partir de seus valores de troca, e não de 
seus valores de uso ${ }^{[8]}$. Entretanto, o autor afirma que esta autonomia pode ser ambígua: ao mesmo tempo em que reafirma os valores burgueses, abre espaço para as resistências, pois sendo a Estética o estudo também das sensações e sentimentos individuais, esta pode se questionar sobre a natureza autodeterminante de poderes e capacidades humanas pela hegemonia não tratados, o que pode ser o fundamento para uma luta de forças. Logo, Eagleton (1993, p. 13) complementa que a Estética pode ser o protótipo secreto da subjetividade na sociedade capitalista incipiente e, ao mesmo tempo, a visão radical das potências humanas com fins em si mesmas, o que combateria (ou ao menos questionaria) o pensamento dominador ou instrumental vigente. No Campo do Design, vemos manifestações e construções de produtos de resistência, como aqueles ligados às estéticas ditas periféricas ou vernaculares no entanto, devemos atentar também ao fato de que a grande indústria cultural apodera-se destas estéticas para reproduzir valores avessos.

$O$ autor considera ainda que a Estética nasceu como um discurso sobre o corpo (EAGLETON, 1993, p. 17): o termo não se refere necessariamente à Arte, já em sua primeira formulação pelo filósofo alemão Baumgarten (1750), mas sim à ideia do termo grego aisthesis, em que a totalidade da percepção e sensação humana é abordada. Assim, a distinção do termo Estética inicialmente é entre o material e o imaterial: entre coisas e pensamentos, sensações e ideias - e é curioso, então, como hoje ligamos a Estética prioritariamente a questões materiais, visuais; provavelmente pela dimensão economicista que tomou frente em suas conceituações e aplicações teórico-práticas - e tal concepção é recorrente e hegemônica no Campo do Design.

Ainda, conforme supracitado, as instâncias políticas dominantes do século XVIII na Europa precisavam de algo que desse conta da vida "sensível", para exercer seu poder e domínio de modo seguro - logo, a emoção deveria ser passível de tradução dentro do escopo da razão. Entretanto, como poderia a razão apreender o que é imaterial, sensual? A razão deveria encontrar um meio, um modo de compreender e coorde- 
nar o mundo da percepção, mas ao fazê-lo, afirma Eagleton (1993, p. 18), deve também atentar a não colocar em risco o seu poder absoluto. Assim, para Baumgarten (apud. EAGLETON, 1993, p. 18), a Estética configura-se como mediadora entre as generalidades da razão e as particularidades dos sentidos, uma fusão entre razão e sentidos e, não obstante as unidades estéticas pudessem ser postas à prova pela análise racional, ainda assim esta análise deveria se dar de uma forma bastante particular, isto é, através dos pressupostos estéticos, da disciplina do conhecimento humano que então começava a tomar forma. Logo, Baumgarten (apud. EAGLETON, 1993, p. 19) considera a Estética como "irmã" da lógica, com a função de ordenar o domínio sensível, da percepção e da experiência em representações claras ou perfeitamente determinadas, de uma forma semelhante à operada pela razão propriamente dita. No Campo do Design, conseguimos observar tal configuração a partir do uso, por exemplo, da metodologia projetual, dos processos de criatividade que dizem orientar a construção estética de produtos de Design.

Assim, segundo Eagleton (1993, p. 21), o que se apresenta em questão é, então, a produção de um novo "sujeito humano", aquele que se apropria da lei como o princípio mesmo de sua autonomia. Logo, estando o poder estetizado, visto que hábitos, devoções dos sentimentos e afetos são determinados e "passam" pelo crivo da razão; torna-se o poder ele mesmo indissociável de impulsos espontâneos, estando imbricado às sensações e naturalizado nos costumes. Deste modo, o autor afirma que o novo sujeito, que doa a si mesmo, a partir de si mesmo, a uma lei indissociável de sua experiência imediata, encontrando sua liberdade na necessidade, é modelado no objeto estético. Assim, em um desenvolvimento histórico, as camadas médias emergentes da sociedade - nem o povo nem a aristocracia - definem-se a si mesmas de modo novo, como sujeito universal (EAGLETON, 1993, p. 26); e no Campo do Design, podemos observar como tal percepção influi não apenas na "prática projetual", em que há regras e diretrizes para a prática estética; como no próprio comportamento profissional dos pares do Campo, ou seja, na necessidade e na imposição de uma identidade para o "ser um designer".

Deste modo, ao configurarem-se as bases para uma aceitação naturalizada de questões estética imbricadas nos objetos de uso cotidiano da 
sociedade capitalista, faz-se necessário esclarecer como esses valores, distintas ideologias presentes em configurações estéticas, são trabalhadas e apresentadas através destes objetos, e quais efeitos sociais e políticos tal realidade pode acarretar - e é isto o que discutiremos a seguir.

\section{A mediação estética}

Janet Wolff, em sua publicação A produção social da Arte (1992), afirma que a Arte é um produto social. Entretanto, compreender que a Arte é produzida socialmente requer o esclarecimento de algumas das maneiras pelas quais suas formas, gêneros e estilos chegam aos valores que Ihes são atribuídos por certos grupos e em determinados contextos. Assim, Wolff (1992, p. 18) afirma que não consegue conceber como uma arte "realmente boa" (aqui podemos tomar como um produto de Design "realmente bom" ou, historicamente, a dita boa forma - Gute Form ${ }^{[9]}$ ) possa ter qualquer relação com proporções da recepção, isto é, como uma arte "realmente boa" possa ser julgada com o gosto dito pessoal, com o julgamento individual de um agente social - mas, do contrário, que as categorias e divisões de uma arte "realmente boa" são criadas, naturalizadas coletivamente por esses agentes e, assim, mantidas historicamente.

Destarte, como esses valores de uma arte boa são criados e mantidos, podemos afirmar que eles trazem consigo relações de valores econômicos, políticos e sociais de seu contexto - trazem e mediam, portanto, ideologias. Os processos sociais e históricos que influenciam a configuração de obras de Arte - ou produtos de Design, por uma homologia ${ }^{[10]}$ entre os Campos da Arte e do Design -, são trazidos à tona quando abandonamos a visão da Arte, do Design, como práticas "acima da história" e as contextualizamos socialmente. Assim, quando significados ocultos são revelados e interesses particulares são trazidos à tona, tornam-se claros, passamos a compre-

[9] Conceito cunhado na Alemanha na década de 1950, mais precisamente no domínio das práticas da Escola de Ulm, que pretendia pensar e produzir objetos com formas e funções ditas "atemporais", os quais resultariam na definição, adoção e reprodução de um "bom gosto" - uma noção idealista de estética que a concebe como funcionalidade, a qual torna-se justificativa do consumo, característica visivelmente imposta pelas esferas econômica e industrial para aumentar a compra e a circulação de produtos. 
ender como elementos estéticos são definidos muito mais por elementos extra-estéticos, conforme discorre Wolff (1982, p. 42), que por questões estéticas propriamente ditas. Logo, a Estética não deve ser estudada e vista apenas por sua lógica interna, prática que incorreria em erro metodológico e teórico, mas sim a partir do contexto e das relações e trocas existentes neste contexto em que ela está inserida e é praticada. Deste modo, deve-se atentar aos elementos extra-estéticos existentes naquilo que supostamente valer-se-ia apenas de julgamento estético, pois a origem e a recepção das obras de Arte e dos produtos de Design tornam-se mais compreensíveis pelas referências às divisões sociais e suas bases econômicas que por supostos valores estéticos abstratos e inalcançáveis, ou incompreensíveis. Ademais, devemos atentar, no Campo do Design, não à forma dos produtos em si e o que ela quer nos dizer semioticamente, mas sim aos valores e códigos sociais intrínsecos ao contexto em que ela é configurada.

Ainda, Wolff (1982, p. 45-49) afirma que a produção coletiva da Arte depende de três fatores principais: a tecnologia, as instituições sociais e os fatores econômicos. É a partir destes fatores que podemos compreender que a produção no Campo do Arte, bem como a produção no Campo do Design, sempre estará atrelada às condições tecnológicas existentes (tipos de materiais e possibilidades de uso); instituições sociais (agentes internos e externos ao Campo profissional que julgam, legitimam o que poderia ser o "bom" ou o "mau" Design, o que pode circular e o que não pode); e fatores econômicos (tanto em questões de produção quanto de recepção - o montante que há disponível para o desenvolvimento de tal produto de Design; ou o montante que determinado agente dispõe para gastar em suas compras, em seu consumo).

A autora também menciona que o caráter ideológico presente nas obras de Arte e nos produtos culturais constitui-se de uma dinâmica complexa, em que a determinação ideológica pode ser mediada tanto pelos grupos sociais quanto pelas suas condições sociais. Assim, a ideologia se expressa na Arte e no Design a partir de duas frentes: 1) nas condições de produção e 2) autonomamente nas convenções estéticas existentes (WOLFF, 1982, p. 73). Ambas, concomitantemente, tornam possível a configuração de uma determinada obra de Arte e/ ou produto de Design e fixam os limites desta configuração. 
Deste modo, quanto às condições da produção artística, Wolff (1982, p. 74) afirma que condições materiais concretas da produção artística, tecnológicas e institucionais mediam a expressão e determinam sua forma específica no produto cultural, ou seja, os materiais disponíveis, a tecnologia vigente e as instituições existentes determinam o que pode e o que será desenvolvido. Obviamente que o caminho não é sempre o mesmo - e por isso há a possibilidade de inovar ou criar no Campo - porém a inovação se dá sempre dentro desses limites definidos, e posteriormente à sua produção, pois ela deve ser legitimada, deve ser reconhecida como tal. Não há ação fora da estrutura pré-determinada, pois nossos valores e nosso modo de pensar são configurados pela estrutura vigente. Logo, as possibilidades de manobra existem, mas sempre existirão dentro desta estrutura que é naturalizada - e no final, o artista ou designer tem pequeno, ou por vezes nulo, controle sobre sua produção, diferentemente do que a noção de gênio criador nos faz acreditar, isto é, que eles têm pleno controle de suas produções criativas. Assim, o nível e as possibilidades de emprego de determinados elementos e configurações estéticas interpõem as próprias mediações entre a ideologia e a expressão cultural, como em um quadro, um romance ou um produto de Design. Entretanto, o que ocorre não é uma simples transposição de ideias políticas, sociais e outras em um veículo estético: essas ideias são trabalhadas esteticamente, determinando a forma do objeto enquanto produto cultural, de acordo com os valores estéticos vigentes. Com efeito, Wolff (1982, p. 74) afirma que o artista, ou designer, é o agente da ideologia, mesmo que inconscientemente.

Em seguida, ao se referir às convenções estéticas, a autora afirma que os códigos estéticos operam como influências mediadoras entre a ideologia e determinadas obras, sobretudo a partir de uma série de regras e convenções que vieram sendo construídas historicamente, que condicionam os produtos culturais e que são usadas por artistas, designers e demais produtores culturais, isto é, elas são relativamente autônomas das condições materiais em vigor (WOLFF, 1982, p. 76). Deste modo, não faz sentido discutir esses códigos por si só, na sua "materialidade" - como a análise semiótica, amplamente utilizada para análises e estudos no Campo do Design, o faz - pois eles não possuem uma lógica interna compreensível, 
exceto se forem contextualizados. O regime ou programa semiótico é indiferente à verdade ou falsidade empírica dos seus conteúdos. Eles só são materiais em sua aparência em determinados contextos, mas sistemas de significação em si, não o são ${ }^{[1]}$. Assim, a ideologia não é expressa em sua "forma pura", mas sim é trabalhada esteticamente, de acordo com as regras e convenções nas quais está ocorrendo a sua produção.

Logo, Wolff (1982, p. 77) determina que a Estética media, portanto, a natureza ideológica da Arte através das condições materiais e sociais de produção e através dos códigos e convenções estéticos existentes, segundo os quais objetos e obras são construídos e configurados. Assim, a ideologia não é simplesmente refletida na Arte, ou no Campo do Design - e não só porque é mediada por inúmeros processos sociais complexos - mas também porque é transformada pelos modos de representação segundo os quais a Arte e o Design são produzidos - e por modos de representação, consideramos aqui aqueles legitimados pelas instâncias de consagração culturais contemporâneas configurados a partir do sistema econômico vigente, que tem grande proximidade do campo cultural. E esta questão quem examina mais profundamente é David Harvey, conforme veremos a seguir.

\section{Variantes extra-estéticas determinantes nas prá- ticas estéticas}

David Harvey, em Condição Pós-Moderna (2010), discorre que a estética do período contemporâneo que vem sendo chamado de pós-moderno, media os valores do sistema econômico vigente, ou seja, o capitalismo em seu estado avançado. Citando PRECIS 6, de 1987 (apud. HARVEY, 2010, p. 45), o autor indica que a cultura da sociedade capitalista avançada passou por uma profunda mudança na estrutura do sentimento, questão inerente a valores estéticos, dito que a Estética toma conta dos estudos das sensações e dos sentimentos, conforme supracitado - e questão inerente também ao Campo do Design, uma vez que ele é um dos prin- 
cipais concretizadores e configuradores contemporâneos dos valores culturais e, consequentemente, estéticos. $\mathrm{O}$ autor ainda cita Huyssens, em 1984 (apud. HARVEY, 2010, p. 45), que afirma que o que é apresentado como o último modismo, promoção publicitária e espetáculo vazio constitui-se como parte de uma lenta transformação cultural emergente em sociedades ocidentais, uma mudança de sensibilidade, de práticas e formações simbólicas distintas das de um período precedente, que aqui ele toma como Modernidade. Assim, nesta mudança de práticas de produção simbólica, considera-se que se deixa de pensar no Homem, a instância universal e racional, para se pensar em escalas menores e mais locais, através de questões mais populares e comerciais que as instâncias abstratas e idealistas do período moderno. Com efeito, Harvey (2010, p. 46) afirma que hoje em dia, é norma procurar estratégias "pluralistas" e "orgânicas" para o desenvolvimento urbano (e acrescentamos aqui, cultural), como "colagem" de espaços e misturas altamente diferenciadas; o que observamos também nos projetos atuais de Design, quando fala-se em Design de Serviços e Design Participativo, que teoricamente teria como intuito projetar para determinado contexto, levando em conta questões intrínsecas àquela realidade - mas que na verdade sabemos nem sempre ocorrer por questões de cunho econômico e político.

Todavia, esta mudança na "estrutura de sentimento" não pode ser tida como uma verdade incontestável, pois não se trata necessariamente de uma substituição de valores modernos por valores ditos pós-modernos: não obstante a fragmentação, a efemeridade e a descontinuidade tenham tomado a frente, ainda há uma mistura de valores de ambos os períodos - e devemos atentar para o modo como estes são sintetizados, estetizados - como suas posições estilísticas se configuram e materializam esses valores. Hassan ${ }^{[12]}$ (apud. HARVEY, 2010, p. 4748), apresenta uma tabela de antagonismos, oposições estilísticas entre moderno e pós-moderno desenvolvida em 1975 - mas não devemos tomá-la como algo simples e direto, pois, conforme supracitado, há nuances. Para ilustrar, o autor toma o exemplo da obra de Arte, construída e 
sólida, que abre espaço para a performance, o happening. No Campo do Design, também podemos ver linhas de Design de Serviços e Design de Experiência tomando a frente das habilitações tradicionais, como Design de Produto e Design Gráfico, fato que ilustra essa mudança de foco e de configuração, de projetos materiais para projetos ditos imateriais, como pensar e, potencialmente, projetar um serviço, o passo a passo de seu desenvolvimento, ou uma experiência.

Harvey (2010, p. 55) também aponta que a minimização da autoridade do produtor cultural na produção de bens culturais cria a oportunidade de uma democratização, de participação popular através de distintos valores culturais - entretanto, o preço de uma certa incoerência nisto abre espaço para uma possível manipulação do mercado de massa, pois o sentido de um produto cultural só é percebido no vestígio entre sua produção e consumo, aspecto que acaba por colocar em xeque os sistemas fixos de representação, ou seja, dos códigos estéticos. Com efeito, já que não é possível uma representação unificada do mundo (e esta recairia em repressão e ilusão, conforme indica o autor), a solução proposta pelos pós-modernistas para uma "ação correta diante do mundo" (HARVEY, 2010, p.55-56) seria valer-se apenas de ações concebidas e decididas nos limites de algum determinismo local, de alguma comunidade interpretativa, porém com seus sentidos fadados a entrar em colapso quando retirados destes domínios isolados, mesmo quando coerentes. Nesta questão, trazemos novamente o uso da dita estética periférica, ou vernacular, tanto por agentes pertencentes a essas realidades, quanto à apropriação da grande indústria com a justificativa seguir ou lançar uma "tendência", isto é, termo que julgamos não ter o menor sentido salvo se for empregado para o aumento do consumo econômico e social, simbólico.

Deste modo, a situação apresentada parece depender de um modo particular de experimentar, interpretar e ser no mundo, de reduzir a experiência a uma série de presentes puros e não relacionados no tempo (HARVEY, 2010, p. 57), em que a imagem, a aparência e o espetáculo podem ser experimentados com intensidade possibilitada apenas pela sua apreciação como imediatismo. Logo, o caráter imediato dos eventos, o sensacionalismo do espetáculo (político, científico, militar ou de diversão) correspondem a uma perda da continuidade histórica de valores e 
crenças. Assim, conforme Harvey (2010, p. 58-59), recusando (e "desconstruindo" ativamente) todos os padrões de autoridade ou supostamente imutáveis de juízo estético, o dito pós-modernismo julga o espetáculo apenas em termos de quão espetacular ele é - e aqui, o Design começa a valer-se também de experiência, de serviços e atitudes momentâneas, e não mais de relações com produtos, artefatos culturais em uma paisagem social; em uma perda de profundidade, uma fixação nas aparências, nas superfícies e nos impactos imediatos que, com o tempo, não tem poder de sustentação (JAMESON, 1984 apud. HARVEY, 2010, p. 59).

Ainda, Harvey (2010, p. 62) discorre sobre a proximidade e a integridade, na pós-modernidade, da cultura com a vida. Há inúmeros pontos de contato entre produtores de artefatos culturais e o público em geral, como a arquitetura, propaganda, moda, filmes, eventos, espetáculos, campanhas políticas, televisão e internet, aspecto que obscurece as influências exercidas entre vida e cultura - quem influencia quem neste processo? 0 autor também afirma que a crescente degeneração da autoridade intelectual sobre o gosto cultural, por exemplo, dos anos 1960 e a sua substituição pela Pop Art, pela cultura pop, pela moda efêmera e pelo gosto da massa, refletem um sinal do hedonismo inconsciente do consumo capitalista, ou então, a imposição do gosto através daquilo que é rentável. Logo, a dita variedade de subculturas, identidades e gostos nada mais reflete que um poderoso comercialismo organizado, em que supostamente há espaço para todos, mas nesse espaço todos devem consumir.

Destarte, em uma relação em que as superfícies são mais importantes que as raízes, a colagem mais relevante que o trabalho em profundidade, as imagens superpostas mais utilizadas que as trabalhadas; um sentido de tempo e espaço decaído toma o lugar do artefato cultural solidamente realizado, e a percepção da história dá-se como uma reserva interminável de evento iguais (TAYLOR, 1987 apud. HARVEY, 2010, p. 63). Conforme Harvey (2010, p. 64), estes aspectos vitais da prática artística na condição pós-moderna dirigem a nossa atenção para a produção de necessidades e desejos (para o Campo do Design, os supracitados Design de Serviços e Design de Experiência), para a mobilização de fantasias, para a política da distração como parte do impulso para manter nos mercados de consumo uma demanda capaz de conservar a lucratividade da produção capitalis- 
ta - ou, conforme Newman (apud. HARVEY, 2010, p. 64), a celebrada fragmentação da Arte (ou, para nós, do Design) já não é uma escolha estética: é somente um aspecto cultural do tecido social e econômico.

Deste modo, podemos observar como no dito pós-modernismo é assinalada uma extensão lógica do poder do mercado a toda a gama de produção cultural. Crimb (apud. Harvey, 2010, p. 64), discorre sobre como as corporações capitalistas tomaram o mundo da Arte, através de interesses econômicos, tornando-se seus principais patrocinadores - e isso é homólogo ao Campo do Design e à museologização de produtos de Design, de artefatos culturais.

Assim, salta aos olhos o viés de que o dito pós-modernismo é construído e atua conforme a lógica cultural do capitalismo avançado, em que a produção da cultura tornou-se integrada à produção de mercadorias em geral. Segundo Mandel (apud. Harvey, 2010, p. 65), a frenética urgência de produzir novas ondas de bens com aparência cada vez mais nova (de roupas a aviões), em taxas de transferência cada vez maiores, agora atribui uma função estrutural mais essencial à inovação e à experimentação estéticas; dinâmica perceptível no Campo do Design.

\section{Considerações finais}

A partir dos escritos de Eagleton (1993), Wolff (1982) e Harvey (2010), podemos compreender como a Estética não constitui-se como um fim em si mesma, ou seja, como os objetos de Design, os artefatos e produtos culturais por ela moldados apresentam-se incutidos de valores ideológicos, tendo suas origens, suas raisons d'être contemporâneas definidas pela lógica econômica e cultural do sistema econômico vigente, isto é, o capitalismo avançado. Destarte, torna-se insustentável conceber que, ainda hoje, no Campo do Design e em outros campos das práticas sociais culturais, imperem as noções de que elementos estéticos podem ser compreendidos e são utilizados a partir de significações intrínsecas, como uma linguagem, desconectadas de suas realidades econômicas e sociais.

Projetar produtos e até mesmo experiências constitui um ato político, mas esta noção e esta responsabilidade não são de conhecimento de todos, pois não há interesse de que isto seja claro - é melhor que os profissionais continuem projetando apenas produtos e experiências 
em suas finalidades próprias. Entretanto, é somente através de uma abertura a este entendimento extra-estético e ideológico dos elementos estéticos empregados na configuração de objetos de Design, de artefatos e produtos culturais, da prática do Campo do Design enquanto produção social (CIPINIUK, 2014) ${ }^{[13]}$, que a sua prática poderá ser melhor compreendida e, acima de tudo, desmistificada - entendida por suas bases reais de existência, e não por seu vazio e sua frivolidade. E tal desmistificação, através da prática social cultural, poderia, mesmo que minimamente, inicialmente ou em um pensamento distante, vir a motivar a configuração de uma nova mudança da estrutura de sentido social, umas vez que esses objetos, produtos e artefatos influenciam e são influenciados, em uma relação dialética, pela sociedade e o momento histórico em que são desenvolvidos e estão inseridos - não obstante a supremacia do sistema econômico pareça ser regra.

\section{Referências}

BOURDIEU, Pierre. O Poder Simbólico. 16a edição.

Rio de Janeiro: Bertrand Brasil, 2012.

A Economia das Trocas Simbólicas.

5a edição. São Paulo: Perspectiva, 2009.

A produção da crença: contribuição para uma

economia dos bens simbólicos. Porto Alegre: Zouk, 2008.

A Distinção: Crítica Social do Julgamento.

São Paulo: Edusp/ Porto Alegre: Zouk, 2007.

CIPINIUK, Alberto. Design: o livro dos porquês: o campo do Design compreendido como produção social. Rio de Janeiro: Ed. PUC-Rio; São Paulo: Ed. Reflexão, 2014.

[13] CIPINIUK, Alberto. Design: o livro dos porquês: o campo do Design compreendido como produção social. Rio de Janeiro: Ed. PUC-Rio; São Paulo: Ed. Reflexão, 2014. 
EAGLETON, Terry. A ideologia da Estética. Rio

de Janeiro: Jorge Zahar Editores, 1993.

FORTY, Adrian. Objetos de Desejo: Design e Sociedade

desde 1750. SãoPaulo: Cosac Naify, 2007.

HARVEY, David. Condição pós-moderna. São Paulo: Loyola, 2010.

WOLFF, Janett. A produção social da arte. Rio

de Janeiro: Zahar Editores,1982. 